\title{
Competency Requirements of Supply Chain Planners and Analysts and Personal Preferences of Hiring Managers
}

Flöthmann, Christoph; Hoberg, Kai; Wieland, Andreas

\author{
Document Version \\ Accepted author manuscript \\ Published in: \\ Supply Chain Management: An International Journal
}

DOI:

10.1108/SCM-03-2018-0101

Publication date:

2018

License

Unspecified

Citation for published version (APA):

Flöthmann, C., Hoberg, K., \& Wieland, A. (2018). Competency Requirements of Supply Chain Planners and Analysts and Personal Preferences of Hiring Managers. Supply Chain Management: An International Journal, 23(6), 480-499. https://doi.org/10.1108/SCM-03-2018-0101

Link to publication in CBS Research Portal

\section{General rights}

Copyright and moral rights for the publications made accessible in the public portal are retained by the authors and/or other copyright owners and it is a condition of accessing publications that users recognise and abide by the legal requirements associated with these rights.

\section{Take down policy}

If you believe that this document breaches copyright please contact us (research.lib@cbs.dk) providing details, and we will remove access to the work immediately and investigate your claim. 


\title{
Competency Requirements of Supply Chain Planners and Analysts and Personal Preferences of Hiring Managers
}

\author{
Christoph Flöthmann, Kai Hoberg, and Andreas Wieland
}

Journal article (Accepted manuscript*)

\section{Please cite this article as:}

Flöthmann, C., Hoberg, K., \& Wieland, A. (2018). Competency Requirements of Supply Chain Planners and Analysts and Personal Preferences of Hiring Managers. Supply Chain Management: An International Journal, 23(6), 480-499. D0I: 10.1108/SCM-03-2018-0101

\section{DOI: 10.1108/SCM-03-2018-0101}

This article is [- Emerald Group Publishing and permission has been granted for this version to appear here: https://research.cbs.dk/en/publications/competency-requirements-of-supply-chain-planners-and-analysts-and

Emerald does not grant permission for this article to be further copied/distributed or hosted elsewhere without the express permission from Emerald Group Publishing Limited.

* This version of the article has been accepted for publication and undergone full peer review but has not been through the copyediting, typesetting, pagination and proofreading process, which may

lead to differences between this version and the publisher's final version AKA Version of Record. 


\title{
Competency requirements of supply chain planners \& analysts and personal preferences of hiring managers
}

\author{
Christoph Flöthmann, Kai Hoberg \& Andreas Wieland
}

\begin{abstract}
Purpose - This study aims to enhance the understanding of competency requirements of supply chain planners and analysts (SCP\&As) and to identify different personal preferences of hiring managers toward job candidates' competency profiles.

Design/methodology - A total of 243 supply chain managers with hiring experience participated in an adaptive choice-based conjoint experiment to uncover the relative importance of six competency attributes, namely analytical \& problem-solving ability, interpersonal skills, general management skills, computer/IT skills, SCM knowledge, and industry experience.

Findings - SCM knowledge and analytical \& problem-solving ability were identified as the most important competencies, and were considered three times more important than general management skills. Based on convergent cluster and ensemble analysis, two types of hiring managers were identified: The first group is characterized by a pronounced preference for job candidates with extensive SCM knowledge. In contrast, the second group's members prefer candidates with a more balanced competency profile.
\end{abstract}

Originality/value - The authors' findings help companies to facilitate a better person-job fit, a key determinant of employee performance and job satisfaction.

Keywords: supply and demand, supply chain management, HR practices 


\section{Introduction}

Having employees whose competencies fit the demands of their job is an essential criterion for company success. This need is reflected in the human resources management (HRM) literature, which suggests that highly-skilled employees can be a strategic resource that facilitates a firm's competitive advantage (Wright et al., 1994; Wright et al., 2001). However, an essential prerequisite to facilitating the strategic use of human resources is finding congruence between employee competencies, job requirements, and the organizational environment - only then can the employee's personal job satisfaction and the employer's performance satisfaction be achieved (Caldwell and O'Reilly III, 1990). Consequently, placing the right people with the right competencies in the right position is a key success determinant of HRM.

Accomplishing a person-job-fit is particularly challenging for supply chain management (SCM) positions (Gattorna, 2006). SCM is a profession that demands an extraordinary combination of competencies, since it links numerous functions within and across companies and manages different flows (i.e., physical, financial, and information) to create value for suppliers, manufacturers, and customers (Mentzer et al., 2001). This is also expressed by the diverse backgrounds and career paths of supply chain managers (Hoberg et al., 2014; Flöthmann and Hoberg, 2017). Moreover, since SCM has evolved into a strategic role only recently (Hult et al., 2007), demands on supply chain personnel have changed (Slone et al., 2007; Fisher et al., 2010). In fact, recruitment, retention, and succession planning are among the major challenges in SCM, in particular because firms and HRM professionals lack an understanding of supply chain talent and their requirements (John, 2015). In response, improving the understanding of crucial SCM competencies would be mutually beneficial for employers and employees as it would increase the likelihood of matching job-related competencies and requirements. 
Although HRM has rarely been represented in the SCM and related literature compared to other research streams, individual competencies have been the scope of the majority of HRM-related studies in SCM (Hohenstein et al., 2014). A recent example for this approach is Derwik and Hellström (2017). Individual competencies have been defined as the combination of knowledge, skills, and abilities (KSAs) that are associated with high individual job performance (Barnes and Liao, 2012). The literature has primarily focused on studying the importance of competencies for various SCM employee groups. Researchers have studied the skills of senior logistics managers (Murphy and Poist, 1991 2007; Razzaque and Sirat, 2001) entry-level logistics personnel (Gibson and Cook, 2003; Murphy and Poist, 2006), supply chain managers (Gammelgaard and Larson, 2001; Mangan and Christopher, 2005; Derwik et al., 2016; Flöthmann et al., 2018), humanitarian logisticians (Kovács et al., 2012), procurement managers (Giunipero et al., 1999; Carr and Smeltzer, 2000; Giunipero and Pearcy, 2000) and, more generally, human capital development in logistics (Myers et al., 2004).

At the same time, no research has yet focused on the competency (Murphy and Poist, 2006) requirements of supply chain planners and analysts (SCP\&As), even though planning, analyzing, and optimizing inventory levels, purchasing volumes, and distribution processes are key activities of SCM (Mentzer et al., 2001). In fact, planning was recently voted the most important activity for supply chains by over 1,000 Chief Supply Chain Officers (O’Marah et al. 2014). The importance of planning is also reflected by the pure number of SCP\&As present in companies. Prior research has analyzed supply chain jobs advertisement and found that the majority of jobs were planning related: Sodhi et al. (2008) found that planning related activities such as inventory management and forecasting were present in 52\% of the analyzed supply chain job ads. Cacciolatti and Molinero (2013) found that more than $60 \%$ of the jobs were planning related. Hence, this paper aims to respond to the scarcity of research on SCP\&As to learn more about their competency requirements and hiring criteria as they shape global supply chains on a daily basis. 
Therefore, the first research question is:

$\boldsymbol{R Q} 1:$ What are the key competency requirements of supply chain planners \& analysts?

To answer this research question, an adaptive choice-based conjoint (ACBC) analysis was applied. This experimental research method is frequently used in marketing to observe consumer preferences for products and services. Compared to the conventional survey methods commonly applied to assessing the importance of various competencies in SCM, ACBC analysis embodies two superior features. First, ACBC analysis forces participants to make complex trade-off decisions between the different attributes, by ranking them according to their relative importance instead of treating them as independent items in a questionnaire (Green et al., 2001). Second, ACBC analysis captures information on the preferences of the experiment's participants by uncovering their individual utility functions toward the attributes. As a result, participants can be segmented according to their utility functions to distinguish between heterogeneous types of hiring managers. This opportunity to conduct an in-depth segmentation analysis relates to our second research question:

RQ 2: Are managers' and firms' preferences homogenous when selecting SCP\&A job candidates, or are they sufficiently distinct to enable segmentation?

To meet these research objectives, a literature review drawing from the knowledge-based view (KBV) of the firm was used to develop the conceptual background for this study. This allows us, based on their value, rareness, inimitability and non-substitutability, to link different competencies of SCP\&As to the sustained competitive advantage of a firm. Subsequently, based on a meta-analysis of the literature on supply chain competencies and an empirical assessment of 200 online SCM job advertisements, six competencies of SCP\&As were identified. To collect the data, an ACBC experiment was conducted with 243 managers possessing experience in SCM employee selection. Ultimately, the key competencies that drive employee selection of SCP\&As were identified, extending the previous literature. 
The remainder of the article is organized as follows. The following section develops the conceptual background to position the paper within the existing literature. Thereafter, the key SCP\&A competencies used in the experiment and the process for developing them are presented. Then, the research methodologies, experimental design, and sampling process are described, the analyses are presented and the results revealed. Finally, insights are discussed and contextualized with regard to the previous knowledge. The article is concluded by providing an outlook on future research opportunities.

\section{Conceptual background and literature review}

\subsection{Human Resources and the Sustained Competitive Advantage of a Firm}

The quest to select highly competent supply chain personnel is grounded in the knowledge-based view $(\mathrm{KBV})$ of the firm. The KBV is based on the idea that knowledge can be a source of competitive advantage for a firm (Kogut and Zander, 1992; Grant, 1996). Research suggests that such strategic knowledge can reside within individuals, i.e., personnel (Grant 1996). Referring to personal knowledge rather than organizational knowledge, "competencies" constitute a more all-embracing terminology since individuals embody the combination of KSAs that they apply at their job and place at the disposal of their employer.

In order to deliver satisfactory performance at work, employees need to possess a sufficient level of KSAs. Within the KSA framework, knowledge refers to the cognitive possession of content or technical information and is typically obtained through formal education, on-the-job experience, and information media (McCormick, 1976). Skills are defined as developed capacities that facilitate learning or the more rapid acquisition of knowledge. One important consequence of this definition is that skills can be trained and are usually acquired "by doing" (Mumford et al., 1999). Lastly, abilities 
are enduring attributes of the individual that influence performance and are not subject to much change (Fossum and Arvey, 1986). A tangible example for an ability would be "talent".

Such competencies, however, only qualify as a source of sustained competitive advantage if they meet four criteria (Barney, 1991): They must be valuable, rare, inimitable, and non-substitutable (these are the so-called "VRIN" characteristics of resources). It has been argued that it is not the human resources practices, but the human resources workforce that form the basis for sustained competitive advantage (Wright et al., 1994).

The HRM literature suggests that those criteria can be fulfilled by capable human resources. First, the economic literature argues that human resources can provide value to their firm (Pfeffer, 1994). They allocate their competencies and time to create value through products and services. Second, capable labor is rare. Studies have suggested that KSAs are approximately normally-distributed in the population (Wright et al., 1994). Exceptionally qualified employees are therefore-by definition — rare (Wright and McMahan, 1992). Third, it is very difficult to imitate highly competent workers because their competency is subjective (tacit) to a large extent and, thus, difficult to conceptualize. It can be referred to as knowing more than we can tell or knowing how to do something without thinking about it (Polanyi, 1966), which makes imitation by or transfer to competitors difficult. Fourth, even in light of technical advancements human resources can be non-substitutable. In fact, despite consistent technological advancements that have led to labor-saving processes and automation, the shift toward a service economy has made human resource substitution less likely (Wright et al., 1994; Huselid, 1995). For the given reasons, HRM should place great emphasis on recruiting and developing top talent, as proficient employees have consistently been linked to organizational and SCM-related performance (Snell and Dean, Jr., 1992; Youndt et al., 1996). By taking a knowledge-based view, top talent is rare, valuable, inimitable and non-substitutable. 


\subsection{Competencies and Employee Selection to Facilitate Person-Job Fit}

Finding capable human resources is a necessary but not sufficient criteria for successful HRM practices. More specifically, firms must facilitate congruence between a person's competencies and a job's demands, which is conceptualized as "person-job fit" (Caldwell and O'Reilly III, 1990). Person-job fit has been positively associated with job performance and job satisfaction (Caldwell and O'Reilly III, 1990). Accordingly, the employee selection practices of most organizations focus on achieving person-job fit (Werbel and Gilliland, 1999). A central element of facilitating this match is the identification of job demands in order to enable recruiters to find the job prospect with the best match. Consequently, a fair share of HRM studies in SCM and logistics have focused on identifying and classifying the most important competencies and recognized it as key factor in human resource selection (Hohenstein et al., 2014; Gatewood et al., 2016). Both literature streams of research on SCM and logistics competencies have been part of our comprehensive literature review for two reasons. First, although both professions need to be distinguished, there is considerable agreement among researchers and practitioners that they are closely related (Larson and Halldórsson, 2004) and demand similar competencies. Second, previous research has consistently studied the competencies of logistics and supply chain managers jointly (Gammelgaard and Larson, 2001; Derwik et al., 2016). Corresponding to this general perception, SCM and logistics competencies have been considered and studied to develop a high-level framework for our experiment of competency requirements for SCP\&As.

As one of the first studies, Murphy and Poist $(1991$; 2007) distinguished between the business, logistics, and management (BLM) skills of entry-level and senior-level logisticians. Their original BLM framework consists of 83 individual skills and knowledge items: 33 business, 18 logistics, and 32 management skills. Overall, the authors conclude that "a contemporary logistician should be a manager first, and a logistician second" (Murphy and Poist 2007, p. 430). In a multi-method study relying on surveys and case studies, Gammelgaard and Larson (2001) studied the skills of logistics 
and supply chain managers. Based on an exploratory factor analysis they grouped 45 skills items as "managerial skills," "SCM core skills," and "quantitative/technical skills." The same framework was later adapted and applied to study the impact of SCM competencies on SCM performance (Flöthmann et al., 2018). Derwik et al. (2016) reveal that supply chain managers use business managerial, generic, and behavioral competences in practice rather than supply chain management expertise.

Importantly, these studies demonstrate that a promising SCM professional has to be reasonably skilled in a large set of dimensions to fulfill their duty, but we argue that this finding is affected by the widespread use of survey methods. The design of questionnaires used in previous studies has often induced participants to deem each skill as either important or very important for SCM. Hence, in many cases there is no statistically significant difference between the item means, which leaves scant room for meaningful interpretation. Moreover, a 5- or 7-point measurement instrument (e.g. Likert scale) only measures absolute importance, studying each item in an isolated state. However, as it is unlikely that all KSAs are in fact equally important; relative importance ratings should play a more prominent role in determining essential job requirements (Gatewood et al., 2016).

When examining the specific competency items that have been researched in the SCM literature, one can observe that the focus has clearly been placed on skills and abilities rather than knowledge or experience (e.g., Gammelgaard and Larson, 2001; Derwik et al., 2016). This focus suggests that, in general, skills and abilities are perceived to be more important than fact-based knowledge in the SCM context. Moreover, we know from the literature that it is more difficult to acquire skills and abilities than fact-based knowledge (Nass, 1994). In conclusion, it will be insightful to observe whether this trend remains if knowledge, skills, and abilities are studied in relation to one another.

Recruitment, selection, and hiring have been subject to a very limited number of studies in the SCM literature (Hohenstein et al., 2014). Among this small sample of papers, no study aims to cover which competencies drive employee selection in SCM through an experimental approach. Rather, previous 
research tries to investigate recruitment and hiring practices and their efficiency in generating large pools of qualified candidates. Gibson and Cook (2003) surveyed logistics firms and logistics graduates to understand whether both groups had a mutual understanding of the requirements of entry-level logistics job positions. Myers et al. (2004) highlighted identifying the best-fitting candidates for various SCM positions as the key challenge for international corporations. As no study has yet focused on the preferences of firms and managers when making employee selection decisions or whether heterogeneity exists among decision makers' preferences, this paper explores these topics.

\section{Identifying key competency attributes}

Developing the key competency attributes that ultimately qualify for the further analysis is one of the most crucial choices when designing conjoint experiments (Orme, 2002; Rao, 2014). Thus, this section describes the dual process used to identify the key competency categories: a literature review and an empirical approach were used.

\subsection{Meta-Analysis of Key Competencies in the Supply Chain Management Context}

Hohenstein et al.'s (2014) recent extensive literature review on HRM issues in SCM was used as the basis for exploring the key competencies of SCM personnel that could be used to design the ACBC experiment. To identify the most important competency items from the literature, six studies (Murphy and Poist 1991, 1998, 2006, 2007; Giunipero and Pearcy 2000; Gammelgaard and Larson 2001) were analyzed and compared, because those studies all used comparable question items and scales to survey SCM professionals, thereby enabling aggregated meta-analysis. Extracting all items led to a list of $269 \mathrm{KSA}$ items. This list was then further condensed.

The condensation process consisted of three steps. First, items were classified and standardized, as the authors used slightly different wording for the same competencies. Second, as the studies also used different scales, the means of all items were normalized to a 5-point scale $(1=$ not important at 
all, $5=$ very important $)$. After those two steps, a short list of 90 competency items emerged. Table 1 provides an overview of the first quartile (i.e., the top $25 \%$ of all items on the short list that scored the highest means across all studies). As conjoint experiments can usually only accommodate six or fewer attributes (Orme, 2002), the first quartile should be sufficient for identifying the most important competencies. As the third condensation step, the competency items were classified by applying the framework proposed by Mangan and Christopher (2005) and adapted by Kovács et al. (2012). The framework suggests using four categories: functional expertise, general management skills, interpersonal skills, and analytical \& problem-solving ability. Those categories also relates to the KSA framework. Functional expertise can be considered knowledge of the function, while analytical \& problem solving ability falls under individual abilities. The other categories can be summarized as skills, the broadest categories that was also subject to the largest number of empirical studies (e.g., Murphy and Poist 1991; Gammelgaard and Larson 2001).

-Insert Table 1 Approximately Here

To ensure high reliability and minimize subjectivity in the categorization process, this process was repeated independently by a second researcher who was familiar with the research topic. The categorizations of both researchers were compared by calculating Cohen's $\kappa$, a statistical measure for inter-rater agreement and reliability (Cohen, 1960; Grayson and Rust, 2001). In this case $\kappa=0.81$ was obtained, which indicates almost perfect inter-rater agreement between both researchers (Landis and Koch, 1977) and, therefore, diminishes the possible threat of subjectivity in the categorization process.

\subsection{Empirical Identification of Job Requirements of Supply Chain Planners and Analysts}

An empirical evaluation of the job requirements of SCP\&As complemented the literature review. Pursuing a dual process should increase the likelihood that the attributes selected for the study cover most of the essential competency dimensions that determine SCP\&A selection. Moreover, due to 
rapid advancements in SCM, an empirical evaluation of current job requirements ensures the relevance of the competencies included in the ACBC experiment. Job advertisements (JAs) were considered a source of information for what companies demand from potential employees. Similar to the approach used by Rossetti and Dooley (2010), the job platforms Monster.com and Monster.co.uk were used to gather JAs for SCP\&As. Monster.com is known to have the highest hit rate for job searchers and has been used for empirical studies addressing various job characteristics (Feldman and Klaas, 2002; Rossetti and Dooley, 2010).

Supply chain planners and supply chain analysts were combined to SCP\&As ex-post after the JA analysis, because JAs for both employee groups matched by $98 \%$. More precisely, the content posted in the JAs was almost identical for both job positions, suggesting that equal competencies are needed for both jobs. The search words "supply (chain) planner," "inventory planner," "demand planner," and "supply chain analyst" were used to find appropriate JAs. JAs were only considered and downloaded if the title contained any of the search terms in full, whereby the order of words did not matter. In the case where a JA was posted under multiple titles, the doubles were eliminated from the sample. Also confidential JAs requiring formal requests, JAs leading to external websites, and ones that did not list any competency requirements were not considered, as they were incompatible with the standard advertisement structure of a Monster.com JA. Following this approach, 200 qualifying JAs were downloaded.

To count the frequency of job requirements in JAs, a cluster retrieval approach was used. Entire sentences mentioning identical competencies with equal or slightly different wording were grouped into similar clusters. Those clusters became the basis of a competency and requirements list, which contained the most relevant KSAs and requirements found in the JA. Figure 1 shows the frequency of competencies derived from the JAs. Interestingly, they diverge from the key competencies in the literature. Function-specific experience, computer/IT skills, and analytical skills are the three most- 
frequently advertised competency requirements. Computer/IT skills were not featured in the first quartile of the meta-analysis, functional knowledge was only represented by one item, and analytical skills were only listed in the twenty-third position. Moreover, industry experience did not emerge from the meta-analysis. The other items shown in Figure 1 match the items obtained from the literature.

-Insert Figure 1 Approximately Here

\subsection{Final Composition of Study Attributes and Levels}

-Insert Figure 2 Approximately Here

We used a consensus solution of the meta-analysis and empirical JA analysis to create the final attributes. Figure 2 visualizes the dual process to identify the six attributes. First, the four competency categories proposed by Mangan and Christopher (2005) and adopted by Kovács et al. (2012) were used in the ACBC experiment as the competency item lists of the meta-analysis (Table 1) supported the notion that this framework adequately covers the spectrum of the most important competencies. Second, those four competencies were supplemented with the two competencies that emerged from the JAs that were not featured in the top quartile of the meta-analysis, i.e., computer/IT skills and industry experience. Computer/IT skills were the second-most mentioned skills among the JAs and deserve attention in the light of the recent technological advancements within SCM (Fawcett et al., 2011). Industry experience was the qualification mentioned second-most among the competencies that were not featured in the literature. Accordingly, it represents an interesting update of Mangan and Christopher's (2005) framework responding to changed demands. Additionally, our framework increases the number of attributes in the "knowledge" category of KSAs, further distinguishing this study from the ones that focused on "skills" (e.g., Murphy and Poist 1991). The definition and the selection of the attributes and levels they can adopt is described as follows. 
Analytical and problem-solving abilities refer to data analysis, conceptualization, number affinity, and information gathering. Computer/IT skills comprise proficiency in Excel, PowerPoint, SAP, ERP, and database tools. General management skills include a broad spectrum of areas, for example project management, supplier/customer relationships, and risk management. Interpersonal skills consist of communication abilities (e.g., listening, verbal, and written), people management, and negotiation. SCM knowledge refers to knowledge in inventory management, logistics network design, as well as sales and operations planning. Industry experience is defined as previous employment in the same company or business unit; previous employment at a direct supplier, customer, or competitor; or a comparable previous relationship to the industry of the respondent's current employer.

For the attributes level, scales comprising three levels each were developed. An identical number of levels across all attributes was chosen to avoid number-of-levels bias, which refers to a respondent's misperception that attributes with more levels are more important than ones with fewer levels (Wittink et al. 1990; Wittink et al. 1992). During the experiment, skills and abilities were rated as one of three levels: "very good," "good," and "basic." Hereby, we chose a positive scale, e.g., by neglecting any level lower than "basic," as such candidates would be disqualified for the job as indicated by previous study results indicating that SCM personnel requirements are very demanding (see, e.g., Gammelgaard and Larson 2001; Murphy and Poist 2007).

Moreover, levels should only cover the real-life spectrum of preferences and, thus, unacceptable levels can be ignored (Orme, 2002). SCM knowledge and industry experience were expressed on the levels "extensive," "some," and "none." In contrast to the skills and ability attributes where some degree of skills or ability had to be present, no functional knowledge might be a realistic scenario for junior planners and analysts who apply straight after graduating university. Accordingly, industry experience might only be an essential requirement in industries with extraordinary product 
specifications. Table 2 shows attribute and level descriptions, as well as examples provided to survey participants to ensure a mutual understanding of the study elements.

-Insert Table 2 Approximately Here

\section{Research design}

\subsection{Adaptive Choice-Based Conjoint Analysis}

$\mathrm{ACBC}$ analysis is a technique that uses choice data and incorporates it into an interview experience for the participant. ACBC analysis is one of the newest advancements in traditional conjoint analysis and has been widely used in marketing research (Green et al., 2001). "Conjoint" originates from "considered jointly," which underscores a major strength of the technique and advantage over the 5or 7-point scales (e.g. Likert scales) used in questionnaires: Instead of surveying items (variables) independently, respondents indicate their preferences while considering all items jointly (Green and Rao, 1971). As a result, this approach can capture complicated trade-offs, in which participants have to make decisions under realistic constraints (Wind et al., 1989). In traditional marketing research, conjoint analysis is used to handle situations in which a decision-maker must deal with several options that vary across multiple attributes (Green et al., 2001). Specifically, it uncovers the utility function of the respondent toward those attributes as well as the partial utility functions of each attribute. In essence, researchers can estimate the importance of attributes relative to one another and the combination of attributes that yields the highest overall utility for the respondent (McFadden, 1986). For example, imagine a manufacturer of laundry detergent that aims to uncover the customers' relative importance ranking toward the product's main attributes price, cleaning power and fragrance. Obviously, all of them are essential criteria for the customers' buying decisions. As a consequence, a questionnaire that is designed to rate the importance of each attribute independently on a discrete scale would fail to uncover valuable insights due to giving the respondent the option to rate all three 
attributes as "very important". This phenomenon was also observed in our meta-analysis of surveybased research as shown in Table 1. A conjoint analysis, in contrast, addresses this phenomenon by challenging the respondents to choose their preferred laundry detergent out of a set of three that differ in price, cleaning power and fragrance, putting the respondents into a more realistic buying situation in front of the supermarket shelf. Repeating this buying situation for several choice sets with varying levels of the three attributes uncovers the individual utility function and the partial utilities of each attribute.

$\mathrm{ACBC}$ is an extension of choice-based conjoint $(\mathrm{CBC})$ analysis. Its popularity is rooted in $\mathrm{CBC}$ analysis' ability to deal with the complexity of choosing among multiple competitive profiles, each of which can vary idiosyncratically across attributes and levels (Green et al., 2001). ACBC utilizes and combines the strengths of $\mathrm{CBC}$ with an adaptive learning experience. More specifically, respondents are presented with choice tasks that were created individually for them based on their own indications given early in the experiment. Coming back to our laundry detergent example, imagine that a particular respondent has repeatedly chosen the product with the lowest price from the choice sets early in the experiment, indicating that they are disregarding the remaining attributes for the decision. In response to this behavior, the ACBC design will adapt and only present options with identical low prices in the following to force the respondents to make his decision based on the remaining attributes (i.e. cleaning power and fragrance). Due to this adaptability, the ACBC design allows to uncover even nuanced preferences for the inferior attributes that would be otherwise masked by the superior attribute (in our example: "price") in non-adaptive experiment designs. Due to the customized design, $\mathrm{ACBC}$ experiments require fewer respondents and observations than $\mathrm{CBC}$ (Toubia et al., 2007) because more information is captured from each individual (Orme, 2009). This is especially advantageous in this study, which targets a set of participants with limited availability (Jervis et al., 2012), in our case supply chain managers who make hiring decisions. 
Results and findings gathered on aggregated full-sample data yield many insights; however, pooled data can mask the importance of relationships between explanatory attributes due to compensatory effects in heterogeneous samples (Hatten et al., 1978). In order to reveal such potential relationships on nuanced levels, respondents should be grouped into homogenous clusters based on their preferences. Subsequently, those groups can be analyzed separately at a disaggregated level. As recommended by multiple sources (Orme and Johnson, 2008; Strehl and Ghosh, 2002), convergent cluster and ensemble analysis (CCEA) was applied to the respondents' individual utility functions to identify heterogeneous groups of managers making employee selections.

\subsection{Experimental Design}

Lighthouse Studio 9 (formerly Sawtooth Software SSI Web) was used to design and execute the ACBC online experiment. The experiment was designed in accordance with the software service providers' suggestions who have conducted and hosted thousands of choice studies (Orme, 2010).

The ACBC experiment consists of three phases (see Figure 3; for screenshots of the experiment see Appendix A). In the first phase (Appendix A.1), the experiment starts with six screening tasks: Four candidate profiles featuring one of the three levels for every attribute are presented. Participants must choose whether each candidate is "a possibility" or "won't work for me." Due to these repetitive indications, the software first gathers information about the respondent's preferences. Between screening tasks, two to three "unacceptable" or "must have" questions can appear (Appendix A.2). Here, participants can indicate whether a certain level is a minimum requirement for them. For example, after candidates with "basic interpersonal skills" were marked as "won't work for me" during the previous screening tasks, the software asks whether "good interpersonal skills" are a minimum requirement. If the respondent offers confirmation, then candidate profiles with less than "good interpersonal skills" won't appear again for the rest of the experiment. Thanks to this logic, the subsequent trade-off decisions are made within the relevant range of levels, which leads to 
information-rich data generation necessary to shift the respondent's utility function toward attributes and levels.

In the second phase, the screening tasks are followed by a choice tournament. A maximum of 14 candidate profiles that emerged from the screening tasks are brought into the choice tournament. In this phase, three candidate profiles from the screening tasks are shown for each of the seven choice sets (Appendix A.3). Respondents are now only allowed to select one candidate out of the three. The selected profile advances to the next choice task, where it faces off against other qualified candidates. Using this repetitive approach, the "ultimate winner" (i.e., the candidate that best meets the respondent's preferences) is identified. To avoid biases from order effects, the sequence of the choice sets and of the attributes are randomized for every participant.

In the third phase, a conventional questionnaire is used to obtain individual and firm-specific demographics and other variables. Those variables - called covariates in conjoint analysis - can be used to explain the different group characteristics obtained with the segmentation analysis. The choice of important covariates is described in detail in the following subsection.

-Insert Figure 3 Approximately Here-

The questionnaire was translated from English to German by one co-author to offer respondents the option of answering in their native language. According to good scientific practice (e.g., Brislin 1976)), another researcher translated the questions back to English to ensure measurement scale equality.

The research design underwent three steps of pre-testing. First, the experiment was simulated with 500 robotic participants, which is a feature integrated into the Lighthouse Studio 9 software. This simulation ensures that the number of choice tasks, the number of attributes, their levels, and the number of level variations across choice sets is sufficient to ensure that rich and accurate data can be 
generated from respondents. Based on this design test, the number of screening tasks (six tasks with four profiles each), must have/unacceptable tasks (maximum three and two, respectively), and choice tasks (seven choices with three profiles each) were chosen. Second, the experiment was pre-tested by five PhD students with backgrounds in SCM and marketing to assess the clarity and conciseness of the instructions and assignments, and the visual appearance of the user interface. Third, the experimental design was assessed by two senior researchers who frequently use conjoint analysis in their research. They confirmed the appropriateness and accuracy of the research design.

\subsection{Covariates}

In conjoint experiments, covariates are individual-level variables that are collected to help explain observed structures in the data, such as the heterogeneity of respondents (Rao, 2014). For this study, a mixture of covariates was chosen to cover a variety of factors that could potentially describe different types of respondents. First, conventional firm-specific demographics used in most contemporary SCM-related studies were chosen as control covariates, namely firm size (measured in number of employees) and industry (e.g., Fullerton et al. 2014). Second, personal demographics, namely country of current job location, business, industry, company experience in years, hierarchical level, and department affiliation were gathered (e.g., Wagner et al. 2012; Fullerton et al. 2014). Third, possible influencing factors pertaining to employee selection were included: the depth of the collaboration between HRM and SCM (as the extent of it might influence selection decisions), their company's overall SCM priorities (as "responsive versus efficient" strategies might have implications for competency requirements), the respondent's functional background (i.e., which function they consider their core backgrounds, such as SCM, logistics, procurement, production, marketing/sales, etc.), and additional qualifications that could be considered important when evaluating potential job candidates ranked by distributing 100 points across the following items: worked for direct competitor,

worked for supplier/customer, international work experience, third language (additional to native language and English proficiency), outstanding university grades, social commitment (e.g., student 
initiative, charitable institution, sports club), among others. Lastly, we asked whether respondents factored possible over-qualification into their assessments of candidates, as this might result in disregarding candidates who scored exceptionally high for many attributes.

\subsection{Sampling and Data Collection}

Potential participants were contacted using the databases of Kühne Logistics University and Copenhagen Business School that include contact details of 2,259 SCM and SCM-related managers. They were contacted by email between April and June 2016 and invited to participate. Fourteen days after first contact, a friendly reminder was circulated to increase the number of responses. After eight weeks in the field, the experiment was completed. In total, 265 completed responses were gathered, reflecting a response rate of $11.7 \%$. However, 22 participants indicated no prior involvement in any employee selection decisions. As the study aims to gather the opinions of knowledgeable respondents with previous hiring expertise only, these unqualified respondents were removed for the subsequent analysis to ensure higher reliability of the data (Forza, 2002). The final sample was 243 responses, with an effective response rate of $10.8 \%$; these figures are comparable to other studies in the field of SCM research (e.g., Wagner et al. 2012) and represent a satisfactory sample size for ACBC analyses (Jervis et al., 2012). Table 3 presents the demographic statistics of our sample.

-Insert Table 3 Approximately Here-

The sample represents a wide variety of industries according to the Industry Classification Benchmark (ICB; FTSE Group, n.d.). Automotive \& Parts, Health Care, and Industrial Goods \& Services are the three most common industries in the sample; together they account for $47.7 \%$ of respondents. The majority of participants work for large or very large companies $(67.9 \%$ of companies in the sample have more than 10,000 employees). Moreover, the typical respondent works in Germany (64.6\%) as a middle manager (48.6\%) in the SCM role (53.9\%), is regularly involved in hiring decisions (57.6\%), and possesses extensive business experience (11-20 years, 44.0\%), 
indicating that the sample consists of knowledgeable participants with the ability to provide informed answers for the experiment. To account for potential non-response bias, the means of the part-worth utilities, question items, and descriptive variables of the first 30 respondents and last 30 respondents were compared using the Mann-Whitney U test (Forza, 2002). The last 30 respondents were treated as a proxy for non-responding managers. No statistically significant differences at the $\mathrm{p}<0.05$ level could be found.

\section{$5 \quad$ Analysis and results}

Hierarchical Bayes (HB) estimation was used to analyze the preferences of participants regarding candidate selection. HB is the premier choice for estimating part-worth utilities on an individual level, due to its estimation accuracy and efficiency (Lenk et al., 1996; Rao, 2014). The ACBC method allows for a two-stage analysis. First, the average preferences for the entire sample were estimated and interpreted. Second, heterogeneity in preferences was explored in the segmentation analysis by distinguishing different types of managers making employee selections.

\subsection{Aggregated Results}

The competency preferences of the aggregated sample (243 responses) were analyzed as a first step. The analysis software integrated in Lighthouse Studio 9 was used to estimate individual part-worth utilities across all 18 attribute levels, as shown in Table 4. The average utilities in the second column are zero-centered, meaning that the sum of all part-worth utilities associated with an attribute equals 0. Table 4 shows attributes in order of importance. The relative importance of each attribute was calculated following a two-step process. First, the value of each attribute was derived by subtracting the utility associated with the lowest level from the utility associated with the highest level of an attribute. Second, the values were normalized so as to sum to $100 \%$. This procedure allows for the comparison of utilities within and across attributes on a common scale (Verma et al., 1999). Results indicate that SCM knowledge and analytical \& problem-solving ability are the two most important 
competencies for an SCP\&A, as indicated by their relative importance values in Table 4. The separate average utilities allow for deeper interpretation of the relative importance of each attribute.

-Insert Table 4 Approximately Here

SCM knowledge is the most important attribute for successful SCP\&As, according to the average utility score $(26.0 \%)$ of all respondents. Hence, respondents, who make real-life hiring decisions, place the greatest emphasis on finding job candidates with a deep understanding of the SCM function. More precisely, “extensive” SCM knowledge (72.3) provides approximately eight times the utility as “some" SCM knowledge (9.7). No SCM knowledge appears to virtually disqualify a candidate entirely (-82.1). This finding is particularly noteworthy, as functional knowledge elements scored relatively low in previous survey-based research papers. Among the 23 top-ranked skills (see Table 1), the only functional knowledge item was "transport \& logistics" (ranked 13). Top-ranked items were heavily weighted toward interpersonal and general management skills. However, in contrast to the skill items listed in Table 1, the finding is in line with online JAs: Function-specific knowledge/experience was the first-most advertised job requirement (Figure 1).

Analytical \& problem-solving abilities yields a quite similar importance (23.8\%) as SCM knowledge. This finding is in accordance with previous studies. Naturally, SCM professionals are widely concerned with data analysis, conceptualization, information gathering, and problem identification. In particular, SCP\&As need the capability to analyze, digest, and interpret large amounts of information. "Basic" analytical and problem-solving abilities are perceived as insufficient for the job $(-79.2)$

Interpersonal skills represent the third-most important competency with 19.1\%. Although SCP\&A's job responsibilities are analytical and data-driven, they are employed in a cross-disciplinary function and thus must possess solid interpersonal skills (e.g., the ability to listen to colleagues from other functions, understand their language, and communicate avidly with all stakeholders to achieve 
common goals that provide maximum value to the firm and supply chain). For instance, due to conflicting key performance indicators (e.g., inventory reduction versus high service levels) that are commonly used in practice, they need to manage and align different people from warehousing, sales, and procurement to make decisions that maximize the benefit of the supply chain.

Computer/IT skills is ranked fourth, yielding a relative importance of $11.2 \%$. This ranking does not correspond to the online JAs for SCP\&As, which mention computer/IT skills as the second most frequent requirement. These discrepancies between respondent preferences and JA content are noteworthy as they might indicate a disconnect between departments: While the JAs promote strong computer proficiency as a key skill requirement, hiring managers making SCP\&A selections only consider it "somewhat" important for the job.

Industry experience is defined as previous work experience or comparable relationships to the same industry (e.g., previous employment in the same company or at a direct competitor). The relative importance score is $10.6 \%$. "Extensive" industry experience is highly valued by experiment participants (31.0) while the value of "some experience" is substantially lower $(-0.6)$, especially in comparison to the second attribute levels of the four attributes discussed above. This indicates that industry experience is only considered valuable for SCP\&A positions if it is extensive, which might be the case if the candidate is a true industry expert. Only possessing some industry experience adds little value.

General management skills are ranked as the least important attribute, at 9.3\%. Apparently, management activities, for example activities such as project management, supplier/customer relationship management, and risk management are not perceived to be as important as the other competencies. However, as the ACBC study design forces participants to make repeated trade-off decisions, some attributes levels must be de-prioritized to a certain extent. This is also reflected in the low utility score of "basic general management skills" (-26.0), translating into the expectation 
that candidates must have better general management skills than that to match the job positions' demands.

The last analytical step performed on the aggregated data was the estimation of a model that included all possible two-way interactions, using the 2-log likelihood test that is suggested to be a sensitive approach for modeling interaction effects between attributes in ACBC analysis (Sawtooth Software, 2016). Assessing interaction effects in cluster analysis may be useful because two-way interactions have the potential to increase the predictive validity of the conjoint model (Green and Srinivasan, 1990). Although four interactions appeared to be significant at the $\mathrm{p}<0.05$ level (interpersonal skills $\times$ analytical \& problem-solving ability, analytical \& problem-solving ability $\times$ SCM knowledge, SCM knowledge $\times$ industry experience, and interpersonal skills $\times$ industry experience), the percentage gains over the additive main effects model for these four interaction terms were only $0.25 \%, 0.11 \%$, $0.07 \%$, and $0.06 \%$, respectively. Sawtooth Software (2016), however, recommend including interaction effects only if they increase the percentage gains for the main effects model by at least $1 \%$. Otherwise, they do not add predictive validity and therefore do not improve the model; indeed, including too many two-way interactions can lead to undesirable overfitting. Consequently, no interaction effects were added to the model shown in Table 4 and described above.

\subsection{Segmentation Analysis}

To account for the heterogeneous preferences of participants, convergent cluster and ensemble analysis (CCEA) was used to segment two types of managers. CCEA is the clustering-method of choice in ACBC analysis as it leverages a combination of multiple clustering approaches to produce a solution that uncovers the most apparent patterns in the data. As a result, the final segments reflect the consensus from a variety of different cluster solutions, hence, an "ensemble of solutions" (Orme and Johnson, 2008). This methodology has been shown to be superior to conventional approaches that rely on a single clustering algorithm, as it produces the most reliable and robust patterns based 
on individual utility functions (Orme and Johnson, 2008; Strehl and Ghosh, 2002). More specifically, our ensemble solution was established using 70 separate cluster solutions, where 14 different cluster solutions $(2-10 ; 12 ; 16 ; 20 ; 25 ; 30)$ were tested with 5 different clustering methods (k-means distance-based start, k-means density-based start, k-means hierarchical-based start; hierarchical average linkage, hierarchical complete linkage) each (Sawtooth Software, 2013).

In this case, the two-cluster solution was reproduced in $93.8 \%$ of all cases over an ensemble of clustering solutions, indicating the solution was robust and had very high validity. The three-cluster, four-cluster, and five-cluster solutions achieved slightly lower reproducibility rates $(81.6 \%, 86.4 \%$, and $85.5 \%$, respectively). In those solutions, both clusters that emerged from the two-cluster solution remained the largest clusters, with only a few cases splitting off to form separate clusters. Moreover, the differences in attribute utilities between the two clusters are most apparent and leave more room for interpreting those preference differences. For the given reasons, the two-cluster solution was chosen for an in-depth analysis. The non-parametric Mann-Whitney U test was used to identify statistically significant difference across both clusters as the part-worth utility values were not normally distributed.

As shown in Table 5, cluster 1, which we label "expert chasers", is the smaller one of the two, comprising $38 \%$ of respondents. Respondents in this cluster place the greatest emphasize on deep SCM knowledge when selecting potential hires. The relative importance of SCM knowledge (39.1\%) is twice as important as the second-ranked attribute, analytical and problem-solving ability (19.1\%), which is still considerably more important than the following attributes. Interpersonal skills and industry experience follow as the next attributes at $11.6 \%$ and $11.2 \%$, respectively. Computer/IT skills $(10.9 \%)$ follow, while general management skills appear least important $(8.0 \%)$, as in the aggregated results (Table 4). In general, this type of senior manager can be described as very demanding, appreciating candidates with the highest level in each attribute. "Extensive" SCM 
knowledge (107.7) adds six times more value to this segment compared to the second highest level, "some" SCM knowledge (17.9), indicating that these hiring managers truly expect deep SCM knowledge from potential hires_-possessing only limited (some) SCM knowledge is perceived as almost worthless. Moreover, extensive SCM knowledge is valued twice as much as the second mostvalued attribute level, namely "very good" analytical \& problem-solving abilities. In addition, possessing "extensive" industry experience as well as "very good" interpersonal, general management, and computer/IT skills is of high importance for these demanding participants.

-Insert Table 5 Approximately Here

Cluster 2, which we call "competency balancers", prefers candidates who possess a more balanced competency profile, i.e., candidates who score "good" or "very good" in almost every attribute. In particular, the six attributes can be further grouped into three subgroups through consideration of their importance percentages. First and foremost, Cluster 2's preferred candidate must combine strong analytical \& problem-solving abilities (26.6\%) with interpersonal skills (23.7\%). Second, they emphasize SCM knowledge (18.0\%) and computer/IT skills (11.4\%). The third category consists of industry experience (10.3\%) and general management skills (10.1\%). A noteworthy similarity is that both clusters rank general management skills last and with similar relative importance. "Very good" analytical and problem-solving abilities (69.4), "very good" interpersonal skills (56.0), and “extensive" SCM knowledge (50.8) provide the greatest utility to this cluster's members. It turns out that "good" interpersonal skills (28.5) are valued as high as "extensive" industry experience (30.3). Additionally, "good" analytical \& problem-solving abilities are ranked higher than "very good" general management skills.

Figure 4 compares the relative attribute importance of both segments by visually highlighting the variation across segments. SCM knowledge clearly dominates the expert chasers' profile. In contrast, the competency balancers place more emphasis on analytical \& problem-solving abilities and 
interpersonal skills attributes, hence balancing out their preferences. Correspondingly, the difference between the most and least important attribute for expert chasers is $31.1 \%$ (SCM knowledge vs. general management skills) compared to only $16.5 \%$ (analytical \& problem-solving ability vs. general management skills) for competency balancers. However, the illustration also visualizes the commonalities across segments. Both groups agree that computer/IT skills, industry experience, and general management skills are of lower relative importance for SCP\&As. Only three covariates differ significantly across the two types of senior managers. The limited ability to explain the different preference types with observable variables suggests that they might be driven by unobserved variables. Possible explanations are discussed in the following section.

-Insert Figure 4 Approximately Here-

\section{Discussion and contextualization}

Although the competencies of personnel in SCM, logistics, and procurement have been studied repeatedly, no research has specifically studied the competencies of SCP\&As nor has an ACBC experiment been employed for that purpose. Our results indicate that the six identified attributes mostly follow the explanations of the knowledge-based view. The following sections aim to discuss and contextualize the study's commonalities with and deviations from previous ones.

\subsection{Meeting the VRIN criteria of the KBV}

As highlighted before, human resources can be evaluated based on their value, rareness, imitability and non-substitutability (Barney, 1991). The results from the ACBC analysis combined with our dual identification of key attributes approach demonstrates that all of the six attributes are valuable. It can be argued, however, that general management skills are widely taught in business schools and industry experience can be gained afterwards, excluding these two attributes from being rare. Moreover, Kavanaugh (2017) asked corporate recruiters to rate the level of proficiency of incoming business school graduates. Here, IT skills ranked highest, indicating that these have become common skills and are not 
rare either. Although a lack of rareness would already exclude a resource from further consideration regarding whether or not it would enable a firm to generate sustained competitive advantage, it can be stated based on the knowledge-based view that resources that have become common and observable also allow others to revise their own skillset: General management skills and industry experience are so common characteristics (thus "general") or that they do not allow firms to become superior over competitors, and, as the results by Kavanaugh (2017) indicate, this seems to become increasingly the case also for computer/IT skills. What is rare, though, is SCM knowledge: The Future of Supply Chain survey (O’Marah and Chen, 2016) shows that it is difficult for more than $80 \%$ of the companies to find as well as to hire talent. An important reason for this is the prevailing discrepancy between SCM talent requirements from industry and the training offered by business schools (Sinha et al., 2016). Other rare attributes are analytical \& problem solving abilities and interpersonal skills: In Kavanaugh's (2017) study proficiencies related to these attributes ranked low and recruiters ranked them substantially lower than in a self-evaluation of students. We argue that these three rare attributes are imperfectly imitable, if at all. SCM knowledge cannot be replaced by other, for example functional knowledge, and while training might help people to improve interpersonal skills and analytical \& problem solving abilities to a certain extent, these attributes tend to be limited innate.

\subsection{Deviations from Previous Studies}

The presented study extends previous academic work. First, SCM knowledge unexpectedly ranked

as the competency with the highest relative importance $(26.0 \%)$. Previous work has repeatedly suggested "soft skills" have greater importance (Harvey and Richey, 2001; Giunipero and Pearcy, 2000; Wu et al., 2013; Derwik et al., 2016). This notion is also reflected in Table 1, which only features one item from the "functional knowledge" category. Also, a study by Flöthmann and Hoberg (2017) on the backgrounds of supply chain executives pointed toward a diverse management career rather than a strong functional background. Executives are less involved in the daily, content-based 
workflows that require deep functional knowledge. Rather, they are more engaged in orchestrating teams, delegating tasks, making decisions, and developing future strategies.

Only one study on skill requirements finds results that are similar to this study’s. Kovács et al. (2012) find in their study on humanitarian logisticians that functional skill items, such as inventory management, warehousing, and transport are more highly ranked than soft skills. Although humanitarian logisticians are a special subgroup of SCM employees that might deal with very different daily challenges than traditional businesses, a comparable prioritization can be found. The use of segmentation to differentiate hiring managers with distinct preferences within a homogenous sample distinguishes this study from previous work and highlight one of ACBC analysis' advantages over conventional survey methods.

\subsection{Inexplicability of Different Preference Types}

An objective of this article was to identify SCM decision makers with different preferences toward a job candidate's competency profile. Although this objective was achieved, a variety of individual and firm-specific covariates describing supply chain strategy, extent of HRM-SCM collaboration, and the reputation of the SCM planning function could not explain the origin and reasons for those differences. Three covariates showed at least weak differences across segments, based on binomial logistics regression analysis. First, competency balancers are not concerned a candidate may be overqualified for a position, whereas expert chasers expressed concerns when faced with a candidate who featured the highest possible levels in each of the six attributes. In particular, expert chasers commented they feared that an overqualified candidate would grow bored by the position's usual duties and rapidly seek other job opportunities. Second, in line with the competency balancers' overall preference for multifaceted talents, they valued evidence of social commitment (such as membership in a student initiative or sports club) as a positive signal, while expert chasers showed no particular preference for this. Third, the functional background of competency balancers and expert chasers 
differs. Respondents with marketing/sales and logistics backgrounds were more likely to belong to the expert chasers group, while respondents with other backgrounds (SCM, procurement, production, or others) are represented roughly equally in both groups. However, given the relatively low Nagelkerke's $\mathrm{R}^{2}$ of 0.112 and weak significance values, additional determinants for preference types likely exist that were either not covered or difficult to reveal. The absence of quantitative explicability might be rooted in the fact that selecting a future member of a team is strongly driven by subjective criteria (Wade and Kinicki, 1997), as hiring managers usually rely on their personal judgement of job-relevant requirements and applicants' competencies (Gatewood et al., 2016). In fact, numerous respondents noted in an open comments field that they also rely on their "gut feeling." Other comments pointed in a similar direction by identifying "sympathy," "chemistry," "personality," and "needs to fit the team," as selection criteria. This raises the question whether firms have standardized guidelines and concepts that outline critical requirements for SCP\&As in place. It can be argued that many firms leave employee selection entirely up to the hiring manager. This approach is surprising as various studies suggest that choosing the right people that meet the requirements of the job is critical to the success of the firm (Caldwell and O'Reilly III, 1990).

\subsection{Post-hoc Analysis}

In order to follow-up on possible additional determinants of preferences, a post-hoc survey was conducted with respondents who voluntarily left their e-mail addresses in the initial experiment, allowing 151 out of the 243 original participants to be contacted, of which 53 completed the post-hoc survey in November 2016. Of those, 17 belonged to the expert chasers and 36 to the competency balancers. The questionnaire gathered additional information on the backgrounds of the current SCP\&A team (which the hypothetical job candidate would supplement), the average employee turnover rate in the team, the performance of the SCP\&A team and the correspondence of the preferred job candidate's background to the respondents. No statistically significant differences were detectable. More importantly, respondents of both groups try to reach the same goals. Both groups 
indicated that they intend to retain new hires as long as possible and identify candidates that perform well as quickly as possible. However, the groups have different opinions about which SCP\&A profiles are more likely to deliver satisfactory performance on the job. Competency balancers assume that multi-faceted talents meet pre-defined performance targets faster and that analytical \& problemsolving abilities and interpersonal skills are most important for their work. In contrast, expert chasers expect that candidates with extensive SCM expertise to be more suitable in those regards. Moreover, competency balancers presume that decent levels of SCM knowledge can be obtained by learning on the job, while expert chasers disagree with that notion.

\section{Conclusions, Limitations, and future research opportunities}

\subsection{Contributions to the Literature}

The study extends the literature in several ways. First - to the best of our knowledge - the competency requirements and selection criteria for SCP\&As, a specific subgroup of SCM personnel that represents the foundation of SCM departments, have not been the objective of an academic paper to date, despite their critical contribution across industries and regions. At the same time, we generate new knowledge on a second subgroup of SCM personnel, which are hiring managers. Thus, we advance the understanding of both which is relevant to make science-based recommendations that can facilitate better person-job fit in practice. At the same time, we respond to recent calls of fellow researchers for more research on the people managing supply chains to understand the SCM talent gap better (Cottrill, 2010; Wieland et al., 2016). To accomplish our goals, we take an interdisciplinary approach that leverages literature, concepts and methods from HRM, SCM and marketing research. Such an innovative approach is necessary to tackle contemporary SCM research problems (Sanders and Wagner, 2011). Second, we link the six studied competencies to the KBV, showing that only three competencies of them meet all four VRIN criteria (SCM knowledge, analytical \& problemsolving ability, and interpersonal skills). Computer/IT skills, industry experience, and general 
management skills are all valuable, but apparently not necessarily rare, inimitable and nonsubstitutable. Hence, according to the principles of the KBV, we show that SCM knowledge, analytical \& problem solving ability, and interpersonal skills can constitute a strategic resource to develop sustained competitive advantage (Barney, 1991). Third, previous insights from survey- and case study-based papers on related SCM personnel groups were extended by investigating and ranking competencies in relation to each other. In that process, the T-shaped competency framework by Mangan and Christopher (2005) frequently used to categorize SCM competency requirements was updated and extended with two additional competencies. Fellow researchers are encouraged to build on the updated version for future studies that meets today's changed requirements more adequately. Fourth, we reveal two groups of hiring managers with distinct preferences toward SCP\&As' competencies. The "expert chasers" are characterized by placing emphasis on candidates' extensive SCM knowledge. In contrast, the "competency balancers" prefer candidates with a more balanced competency profile. This finding presents empirical evidence for Derwik et al.'s (2016) proposition that states that companies might consider both generalists and specialists when making employee selection decisions in SCM.

Fifth, ACBC analysis was introduced to the SCM literature as an innovative research methodology.

\subsection{Managerial Implications}

The study's results have multiple managerial implications. Although firms invest in strategic recruitment activities and advanced selection methods such as assessment centers and case studies, the findings suggest that SCP\&A selection is often driven by an interviewer's subjective criteria. Multiple objective covariates were not able to measure or explain the determinants of different preferences toward a candidate's competencies. In response, firms' HRM and SCM experts should invest joint efforts to define objective requirements to ensure a candidate's profile matches the needs, strategic goals, and organizational culture. Companies should ultimately strive to form organization- 
wide recruitment and selection policies with precisely defined requirements for different job positions that reduce the influence of subjective criteria. Moreover, the differences between the competency requirements most frequently highlighted in online JAs (computer/IT skills, see Figure 1) and the relative importance of these attributes as indicated by the study results (only 11.2\%) show a disconnect between SCM and HRM, supporting the concerns raised by our research outlined above (Cottrill and Rice Jr., 2012; Fisher et al., 2010). In other words, SCP\&A JAs do not adequately reflect the candidate profiles desired by hiring managers. Unqualified candidates might apply while qualified ones might not. In response, HRM and SCM should facilitate closer collaboration to design appropriate JAs that increase the number of applications that actually meet the demands of the position and the preferences of hiring managers.

\subsection{Limitations and Future Research Opportunities}

This study had certain limitations. First, only six competency attributes could be included in the study, due to the experimental design constraints of conjoint studies. In general, KSA are multidimensional and expressed by numerous facets, which makes aggregation to a few categories difficult. For the same reasons, competencies were the only job selection criteria included in the experimental design. However, given that most of the existing literature has used surveys, the previously-described upsides of the ACBC analysis approach outweigh the downsides, as this study extends existing knowledge on SCM competencies. Second, although this study focuses on a specific SCM employee group, planning and analysts jobs might differ by company, depending on various circumstances and business environments. Consequently, the competency requirements are not generalizable per se to any planner and analyst position. However, the attempt to incorporate six broad competency attributes should reduce this limitation.

This paper opens up potential avenues for future research. This study focuses on the selection criteria for hypothetical candidates without considering the team composition of the recruiting company. 
Accordingly, employee selection criteria could be studied on a firm level under consideration of the competency profiles of entire teams. From a methodological perspective, the research design could be replicated with other employee groups in SCM. The opportunities for application of ACBC analysis go far beyond that, though. For instance, fellow scholars could adopt the method to study determinants of supplier, service provider, and strategic partner selection in supply chains.

\section{References}

Barnes, J., and Liao, Y., (2012), "The effect of individual, network, and collaborative competencies on the supply chain management system", International Journal of Production Economics, Vol. 140 No. 2, pp. 888-899.

Barney, J.B., (1991), "Firm resources and sustained competitive advantage", Journal of Management, Vol. 17 No. 1, pp. 99-120.

Brislin, R.W., (1976), "Comparative research methodology: cross-cultural studies", International Journal of Psychology, Vol. 11 No. 3, pp. 215-229.

Cacciolatti, L., and Molinero, C.M., (2013), "Analysing the demand for supply chain jobs through job advertisements", University of Kent Working Paper Series, No. 264.

Caldwell, D.F., and O'Reilly III, C.A., (1990), "Measuring person-job fit with a profile-comparison process", Journal of Applied Psychology, Vol. 75 No. 6, pp. 648-657.

Carr, A.S., and Smeltzer, L.R., (2000), "An empirical study of the relationships among purchasing skills and strategic purchasing, financial performance, and supplier responsiveness", Journal of Supply Chain Management, Vol. 36 No. 2, pp. 40-54.

Cohen, J., (1960), "A coefficient of agreement for nominal scales", Educational and Psychological Measurement, Vol. 20 No. 1, pp. 37-46.

Cottrill, K., (2010), "Are you prepared for the supply chain talent crisis?", MIT Center for Transportation and Logistics, MIT CTL White Paper, Vol. Fall, pp. 1-11.

Cottrill, K., and Rice Jr., J.B., (2012), "Supply chain talent management: adressing the HR disconnect", MIT Center for Transportation and Logistics, MIT CTL White Paper, Vol. Winter, pp. $1-16$.

Derwik, P., and Hellström, D., (2017), "Competence in supply chain management: a systematic review", Supply Chain Management: An International Journal, Vol. 22 No. 2, pp. 200-218.

Derwik, P., Hellström, D., and Karlsson, S., (2016), "Manager competences in logistics and supply chain practice", Journal of Business Research, Vol. 69 No. 11, pp. 4820-4825.

Fawcett, S.E., Wallin, C., Allred, C., Fawcett, A.M., and Magnan, G.M., (2011), "Information technology as an enabler of supply chain collaboration: A dynamic-capabilities perspective", Journal of Supply Chain Management, Vol. 47 No. 1, pp. 38-59.

Feldman, D.C., and Klaas, B.S., (2002), "Internet job hunting: a field study of applicant experiences with on-line recruiting", Human Resource Management, Vol. 41 No. 2, pp. 175-192.

Fisher, S.L., Graham, M.E., Vachon, S., and Vereecke, A., (2010), "Guest editors' note: don't miss the boat: research on HRM and supply chains", Human Resource Management, Vol. 49 No. 5, pp. 813-828. 
Flöthmann, C., and Hoberg, K., (2017), "Career patterns of supply chain executives: an optimal matching analysis", Journal of Business Logistics, Vol. 38 No. 1, pp. 35-54.

Flöthmann, C., Hoberg, K., and Gammelgaard, B., (2018), "Disentangling supply chain management competencies and their impact on performance: a knowledge-based view", International Journal of Physical Distribution \& Logistics Management, Vol. 48 No. 6, pp. 630-655.

Forza, C., (2002), "Survey research in operations management: a process-based perspective", International Journal of Operations \& Production Management, Vol. 22 No. 2, pp. 152-194.

Fossum, J., and Arvey, R., (1986), "Modeling the skills obsolescence process: A psychological/economic integration", Academy of Management Review, Vol. 11 No. 2, pp. 362374.

FTSE Group Industry Classification Benchmark,. http://www.icbenchmark.com/, Accessed April 2, 2013,.

Fullerton, R.R., Kennedy, F.A., and Widener, S.K., (2014), "Lean manufacturing and firm performance: the incremental contribution of lean management accounting practices", Journal of Operations Management, Vol. 32 No. 7-8, pp. 414-428.

Gammelgaard, B., and Larson, P.D., (2001), "Logistics skills and competencies for supply chain management", Journal of Business Logistics, Vol. 22 No. 2, pp. 27-50.

Gatewood, R.H., Feild, H.S., and Barrick, M., (2016), Human Resource Selection, 8th ed., South Western, Australia.

Gattorna, J., (2006), Living supply chains, Prentice Hall Financial Times, Harlow, UK.

Gibson, B.J., and Cook, R.L., (2003), "Entry-level logistics management hiring issues", International Journal of Retail \& Distribution Management, Vol. 14 No. 1, pp. 121-134.

Giunipero, L.C., Dawley, D., and Anthony, W.P., (1999), "The impact of tacit knowledge on purchasing decisions", Journal of Supply Chain Management, Vol. 35 No. 4, pp. 42-49.

Giunipero, L.C., and Pearcy, D.H., (2000), "World-class purchasing skills: An empirical investigation", Journal of Supply Chain Management, Vol. 36 No. 4, pp. 4-13.

Grant, R., (1996), "Toward a knowledge-based theory of the firm", Strategic Management Journal, Vol. 17 No. S2, pp. 109-122.

Grayson, K., and Rust, R., (2001), "Interrater reliability", Journal of Consumer Psychology, Vol. 10 No. 1-2, pp. 71-73.

Green, P.E., Krieger, A.M., and Wind, Y., (2001), "Thirty years of conjoint analysis: reflections and prospects", Interfaces, Vol. 31 No. 3, pp. 56-73.

Green, P.E., and Rao, V., (1971), "Conjoint measurement for quantifying judgmental data", Journal of Marketing Research, Vol. 8 No. 3, pp. 355-363.

Green, P.E., and Srinivasan, V., (1990), "Conjoint analysis in marketing: new developments with implications for research and practice", Journal of Marketing, Vol. 54 No. 4, pp. 3-19.

Harvey, M.G., and Richey, R.G., (2001), "Global supply chain management: The selection of globally competent managers", Journal of International Management, Vol. 7 No. 2, pp. 105128.

Hatten, K.J., Schendel, D.E., and Cooper, A.C., (1978), "A strategic model of the U.S. brewing industry: 1952-1971", Academy of Management Journal, Vol. 21 No. 4, pp. 592-610.

Hoberg, K., Alicke, K., Flöthmann, C., Lundin, J. (2014), "The DNA of supply chain executives." Supply Chain Management Review, Vol. 18 No.6, pp. 36-44.

Hohenstein, N.-O., Feisel, E., and Hartmann, E., (2014), "Human resource management issues in supply chain management research: a systematic literature review from 1998 to 2014", International Journal of Physical Distribution \& Logistics Management, Vol. 44 No. 6, pp. 434 463. 
Hult, G.T.M., Ketchen Jr., D.J., and Arrfelt, M., (2007), "Strategic supply chain management: improving performance through a culture of competitiveness and knowledge development", Strategic Management Journal, Vol. 28 No. 10, pp. 1035-1052.

Huselid, M.A., (1995), "The impact of human resource management practices on turnover, productivity, and corporate financial performance", Academy of Management Journal, Vol. 38 No. 3, pp. 635-672.

Jervis, S.M., Ennis, J.M., and Drake, M.A., (2012), "A comparison of adaptive choice-based conjoint and choice-based conjoint to determine key choice attributes of sour cream with limited sample size", Journal of Sensory Studies, Vol. 27 No. 6, pp. 451-462.

John, G., (2015), Developing Supply Chain Capability - Findings of the Talent Survey 2015, SCM World, London.

Kavanaugh, J., (2017), "Are Students Getting the Most from MBA Programs?", http://jeffkavanaugh.net/mba-programs-preparing-students-success/, Accessed December 11th, 2017 ,.

Kogut, B., and Zander, U., (1992), "Knowledge of the firm, combinative capabilities, and the replication of technology", Organization Science, Vol. 3 No. 3, pp. 383-397.

Kovács, G., Tatham, P., and Larson, P., (2012), "What skills are needed to be a humanitarian logistician?", Journal of Business Logistics, Vol. 33 No. 3, pp. 245-258.

Landis, J.R., and Koch, G.G., (1977), "The measurement of observer agreement for categorical data.", Biometrics, Vol. 33 No. 1, pp. 159-174.

Larson, P., and Halldórsson, Á., (2004), "Logistics versus supply chain management: An international survey", International Journal of Logistics Research and Application, Vol. 7 No. 1, pp. 37-41.

Lenk, P.J., DeSarbo, W.S., Green, P.E., and Young, M.R., (1996), "Hierarchical Bayes conjoint analysis: recovery of partworth heterogeneity from reduced experimental designs", Marketing Science, Vol. 15 No. 2, pp. 173-191.

Mangan, J., and Christopher, M., (2005), "Management development and the supply chain manager of the future", The International Journal of Logistics Management, Vol. 16 No. 2, pp. 178-191.

McCormick, E.J., (1976), "Job and task analysis", in Dunnelle, M. D. (Ed.), Handbook of Industrial and Organizational Psychology, Rand McNall, Chicago, pp. 651-696.

McFadden, D., (1986), "The choice theory approach to market research", Marketing Science, Vol. 5 No. 4, pp. 275-297.

Mentzer, J.T., DeWitt, W., Keebler, J.S., Min, S., Nix, N.W., Smith, C.D., and Zacharia, Z.G., (2001), "Defining supply chain management", Journal of Business Logistics, Vol. 22 No. 2, pp. 1-25.

Mumford, M.D., Peterson, N.G., and Childs, R.A., (1999), "Basic and cross-functional skills", in Peterson, N. G. and Mumford, M. D. (Ed.), An occupational information system for the 21st century: The development of $O * N E T$, merican Psychological Association, Washington D.C., pp. 49-69.

Murphy, P.R., and Poist, R.F., (2006), "Skill requirements of contemporary senior-and entry-level logistics managers: a comparative analysis", Transportation Journal, Vol. 45 No. 3, pp. 46-60.

Murphy, P.R., and Poist, R.F., (2007), "Skill requirements of senior-level logisticians: a longitudinal assessment", Supply Chain Management: An International Journal, Vol. 12 No. 6, pp. 423-431.

Murphy, P.R., and Poist, R.F., (1998), "Skill requirements of senior-level logisticians: practitioner perspectives", International Journal of Physical Distribution \& Logistics Management, Vol. 21 No. 4, pp. 284-301.

Murphy, P.R., and Poist, R.F., (1991), "Skill requirements of senior-level logistics executives: an empirical investigation", Journal of Business Logistics, Vol. 12 No. 2, pp. 73-95.

Myers, M.B., Griffith, D.A., Daugherty, P.J., and Lusch, R.F., (2004), "Maximizing the human 
capital equation in logistics: education, experience, and skills", Journal of Business Logistics, Vol. 25 No. 1, pp. 211-232.

Nass, C., (1994), "Knowledge or skills: which do administrators learn from experience?", Organization Science, Vol. 5 No. 1, pp. 38-50.

O’Marah, K., and Chen, X., (2016), Future of Supply Chain, SCM World, London.

O’Marah, K., John, G., Blake, B., and Manenti, P., (2014), The Chief Supply Chain Officer Report 2014: Pulse of the Profession, SCM World, London.

Orme, B.K., (2002), "Formulating attributes and levels in conjoint analysis", Sawtooth Software Research Paper Series, pp. 1-4.

Orme, B.K., (2010), Getting started with conjoint analysis: strategies for product design and pricing research, 2nd ed., Research Publishers LLC, Madison, Wi.

Orme, B.K., (2009), "Which conjoint method should I use?", Sawtooth Software Research Paper Series, , pp. 1-6.

Orme, B.K., and Johnson, R., (2008), "Improving k-means cluster analysis: ensemble analysis instead of highest reproducibility replicates", Sawtooth Software Research Paper Series, pp. 1-11.

Pfeffer, J., (1994), "Competitive advantage through people", California Management Review, Vol. 36 No. 2, pp. 9-28.

Polanyi, M., (1966), The Tacit Dimension, Doubleday, Garden City, NY.

Rao, V.R., (2014), Applied Conjoint Analysis, Springer, Berlin Heidelberg.

Razzaque, M.A., and Sirat, M.S. Bin, (2001), "Skill requirements: perception of the senior Asian logisticians", International Journal of Physical Distribution \& Logistics Management, Vol. 31 No. 5, pp. 374-395.

Rossetti, C., and Dooley, K., (2010), "Job types in the supply chain management profession", Journal of Supply Chain Management, Vol. 46 No. 3, pp. 40-56.

Sanders, N.R., and Wagner, S.M., (2011), "Multidisciplinary and multimethod research for addressing contemporary supply chain challenges", Journal of Business Logistics, Vol. 32 No. 4, pp. 317-323.

Sawtooth Software (2013), CCEA v3, Orme, B. K. (Ed.), Sawtooth Software, Inc., Orem, Ut.

Sawtooth Software (2016), Lighthouse Studio v9.0, Orme, B. K. (Ed.), Sawtooth Software, Inc., Orem, Ut.

Simon, H.A., (1991), "Bounded rationality and organizational learning", Organization Science, Vol. 2 No. 1, pp. 125-134.

Sinha, A., Millhiser, W.P., and He, Y., (2016), "Matching supply with demand in supply chain management education", The International Journal of Logistics Management, Vol. 27 No. 3, pp. 837-861.

Slone, R., Mentzer, J., and Dittmann, J., (2007), "Are you the weakest link in your company's supply chain?", Harvard Business Review, Vol. 85 No. 9, pp. 116-127.

Snell, S.A., and Dean, Jr., J.W., (1992), "Integrated manufacturing and human resource management: a human capital perspective", Academy of Management Journal, Vol. 35 No. 3, pp. 467-504.

Sodhi, M.M.S., Son, B.G., and Tang, C.S., (2008), "ASP, the art and science of practice: what employers demand from applicants for MBA-level supply chain jobs and the coverage of supply chain topics in MBA courses", Interfaces, Vol. 38 No. 6, pp. 469-484.

Strehl, A., and Ghosh, J., (2002), "Cluster ensembles - a knowledge reuse framework for combining multiple partitions", Journal of Machine Learning Research, Vol. 3 No. Dec, pp. 583-617.

Toubia, O., Hauser, J., and Garcia, R., (2007), "Probabilistic polyhedral methods for adaptive choicebased conjoint analysis: Theory and application", Marketing Science, Vol. 26 No. 5, pp. 596610. 
Verma, R., Thompson, G.M., and Louviere, J.J., (1999), "Configuring service operations in accordance with customer needs and preferences", Journal of Service Research, Vol. 1 No. 3, pp. 262-274.

Wade, K.J., and Kinicki, A.J., (1997), "Subjective applicant qualifications and interpersonal attraction as mediators within a process model of interview selection decisions", Journal of Vocational Behavior, Vol. 40 No. 50, pp. 23-40.

Wagner, S.M., Grosse-Ruyken, P.T., and Erhun, F., (2012), "The link between supply chain fit and financial performance of the firm", Journal of Operations Management, Vol. 30 No. 4, pp. 340353.

Werbel, J.D., and Gilliland, S.W., (1999), "Person-environment fit in the selection process", Research in Personnel and Human Resources Management, Vol. 17, pp. 209-243.

Wieland, A., Handfield, R.B., and Durach, C.F., (2016), "Mapping the landscape of future research themes in supply chain management", Journal of Business Logistics, Vol. 37 No. 3, pp. 205212.

Wind, J., Green, P.E., Shifflet, D., and Scarbrough, M., (1989), "Courtyard by Marriott: designing a hotel facility with consumer-based marketing models", Interfaces, Vol. 19 No. 1, pp. 25-47.

Wittink, D., Huber, J., Zandan, P., and Johnson, R.M., (1992), "The number of levels effect in conjoint: where does it come from and can it be eliminated?", Sawtooth Software Research Paper Series, pp. 1-11.

Wittink, D.R., Krishnamurthi, L., and Reibstein, D.J., (1990), "The effect of differences in the number of attribute levels on conjoint results", Marketing Letters, Vol. 1 No. 2, pp. 113-123.

Wright, P.M., Dunford, B.B., and Snell, S.A., (2001), "Human resources and the resource based view of the firm", Journal of Management, Vol. 27 No. 6, pp. 701-721.

Wright, P.M., and McMahan, G.C., (1992), "Theoretical perspectives for strategic human resource management", Journal of Management, Vol. 18 No. 2, pp. 295-320.

Wright, P.M., McMahan, G.C., and McWilliams, A., (1994), "Human resources and sustained competitive advantage", International Journal of Human Resource Management, Vol. 5 No. 2, pp. 301-326.

Wu, Y.-C.J., Huang, S.K., Goh, M., and Hsieh, Y.-J., (2013), "Global logistics management curriculum: perspective from practitioners in Taiwan", Supply Chain Management: An International Journal, Vol. 18 No. 4, pp. 376-388.

Youndt, M.A., Snell, S.A., Dean, Jr., J.W., and Lepak, D.P., (1996), "Human resource management, manufacturing strategy, and firm performance.", Academy of Management Journal, Vol. 39 No. 4, pp. 836-866. 


\section{Appendix A: Screenshots of experiment design}

\section{A.1 Example of screening task}

Here are a few candidates you might like. For each one, please indicate whether it is a possibility or not. (1 of 6)

\begin{tabular}{|c|c|c|c|c|}
\hline Interpersonal skills & Basic & Basic & Good & Very good \\
\hline $\begin{array}{l}\text { Analytical and problem- } \\
\text { solving ability }\end{array}$ & Basic & Good & Very good & Basic \\
\hline Computer / IT skills & Good & Very good & Basic & Basic \\
\hline SCM knowledge & Extensive & Extensive & Some & None \\
\hline General management skills & Good & Good & Good & Very good \\
\hline \multirow[t]{3}{*}{ Industry experience } & None & None & Some & Extensive \\
\hline & A possibility & A possibility & A possibility & A possibility \\
\hline & Won't work for me & Won't work for me & Won't work for me & Won't work for me \\
\hline
\end{tabular}

Helpful links: Attribute definition I Level definition
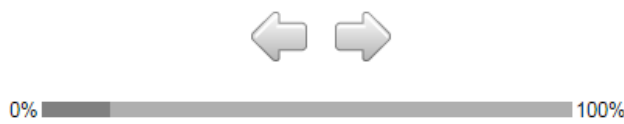

\section{A.2 Example of unacceptable attribute levels}

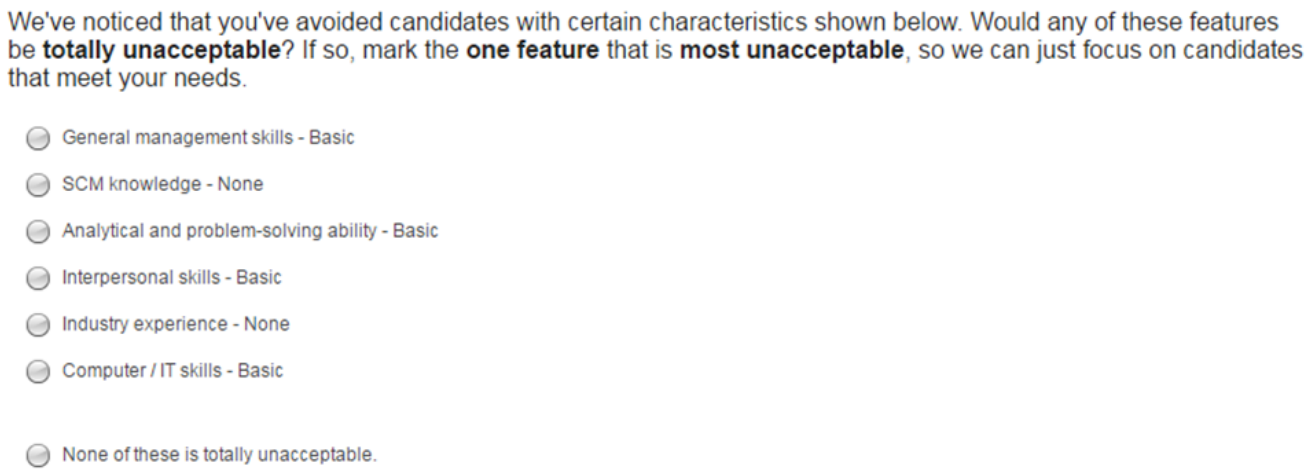

We've noticed that you've avoided candidates with certain characteristics shown below. Would any of these features be totally unacceptable? If so, mark the one feature that is most unacceptable, so we can just focus on candidates that meet your needs.

$\bigcirc$ General management skills - Basic

ScM knowledge - None

Analytical and problem-solving ability - Basic

Interpersonal skills - Basic

Industry experience - None

Computer /IT skills - Basic

None of these is totally unacceptable. 


\section{A.3 Example of Choice Tournament Task}

\begin{tabular}{|c|c|c|c|}
\hline \multicolumn{4}{|c|}{$\begin{array}{l}\text { Among these three, who is the best option for you? } \\
(2 \text { of } 7)\end{array}$} \\
\hline Interpersonal skills & Very good & Good & Very good \\
\hline $\begin{array}{l}\text { Analytical and problem- } \\
\text { solving ability }\end{array}$ & Very good & Good & Very good \\
\hline Computer / IT skills & Good & Very good & Good \\
\hline SCM knowledge & Extensive & Extensive & Some \\
\hline General management skills & Good & Good & Very good \\
\hline Industry experience & Some & Some & Extensive \\
\hline & 0 & 0 & 0 \\
\hline \multicolumn{4}{|c|}{ Helpful links: Attribute definition I Level definition } \\
\hline
\end{tabular}




\section{FIGURES AND TABLES}

\section{FIGURE 1: SHARE OF KEY JOB REQUIREMENTS FEATURED IN ONLINE JOB ADVERTISEMENTS}

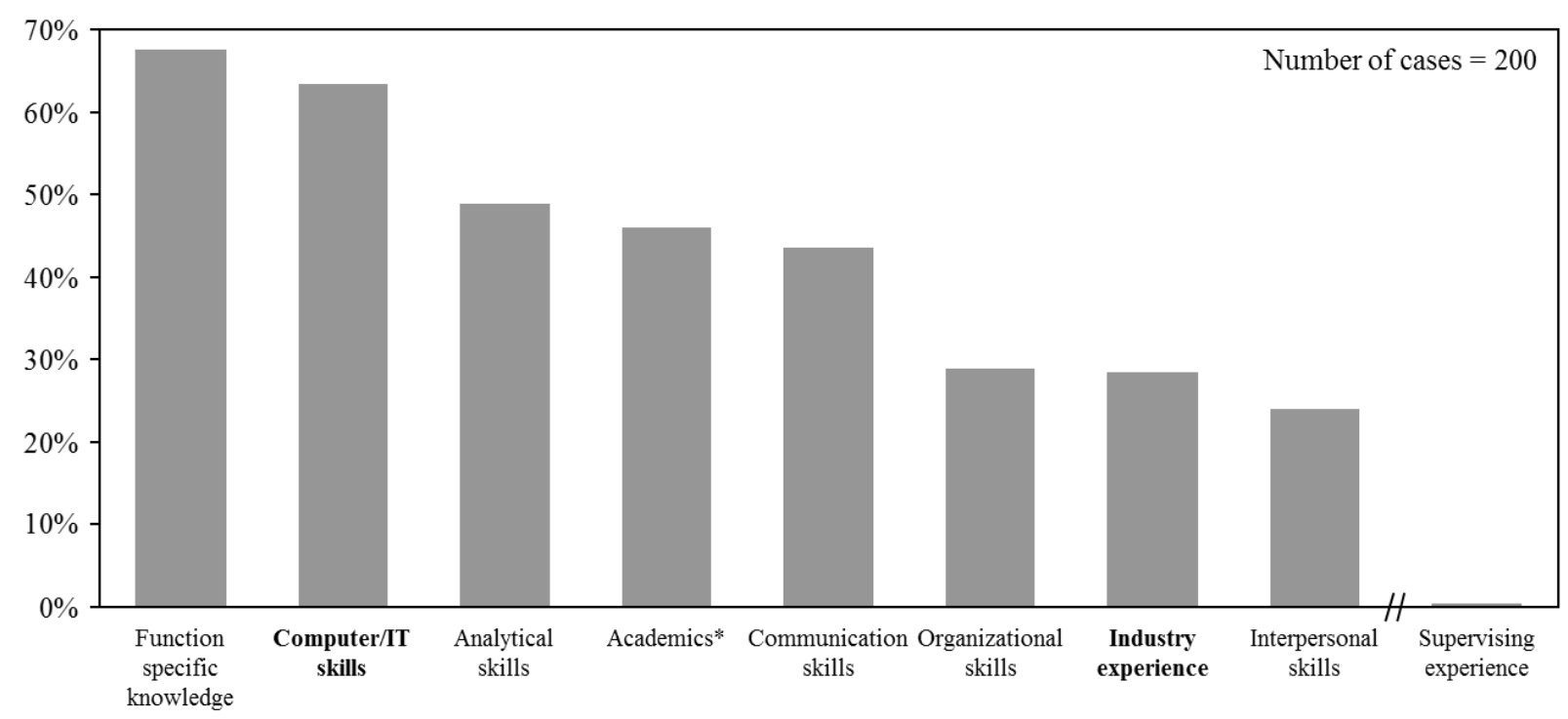

Note: Competencies in bold did not emerge from the meta-analysis, i.e., they reflect a deviation between academic studies and company JA postings. The other items were represented in the literature as well. *The job requirement "Academics" was not considered for the experiment as it represents education rather than competency. 
FIGURE 2: METHODOLOGICAL DUAL PROCESS TO IDENTIFY KEY COMPETENCIES

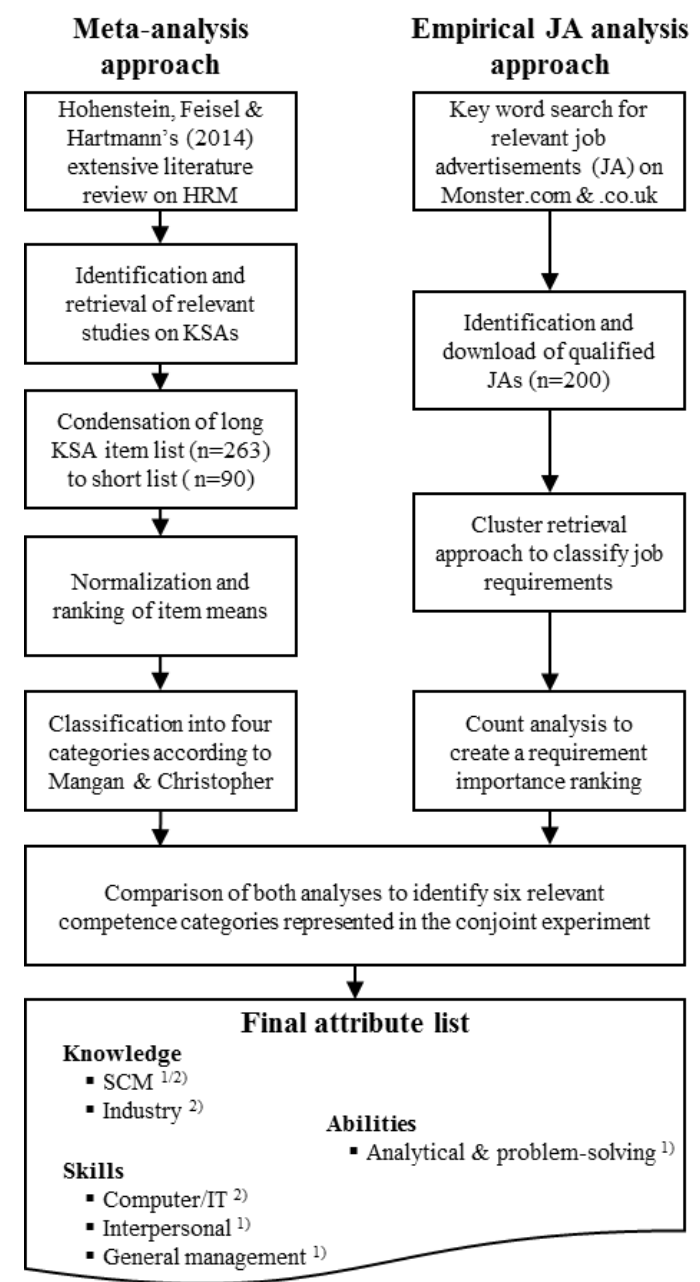

Notes: 1) emerged from meta-analysis, 2) emerged from empirical JA analysis

\section{Figure 3: Phases of The ACBC EXPeriment}

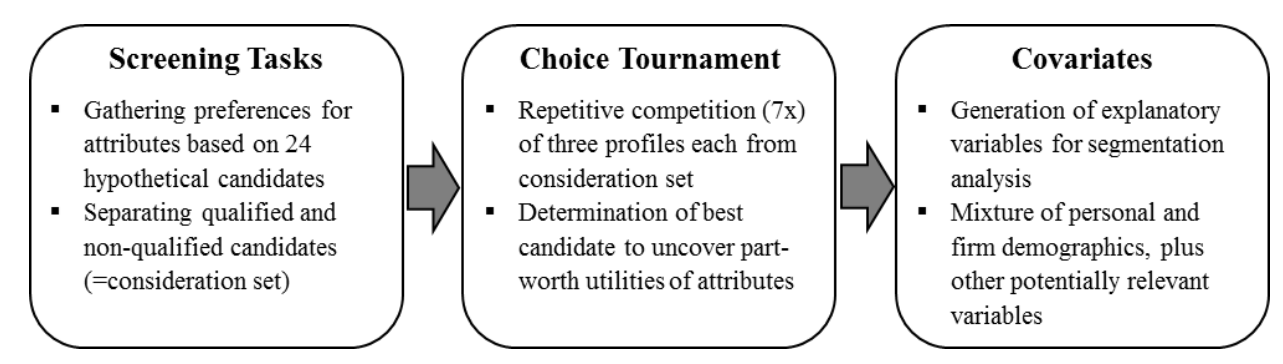


FIGURE 4: RELATIVE IMPORTANCE COMPARISON ACROSS SEGMENTS

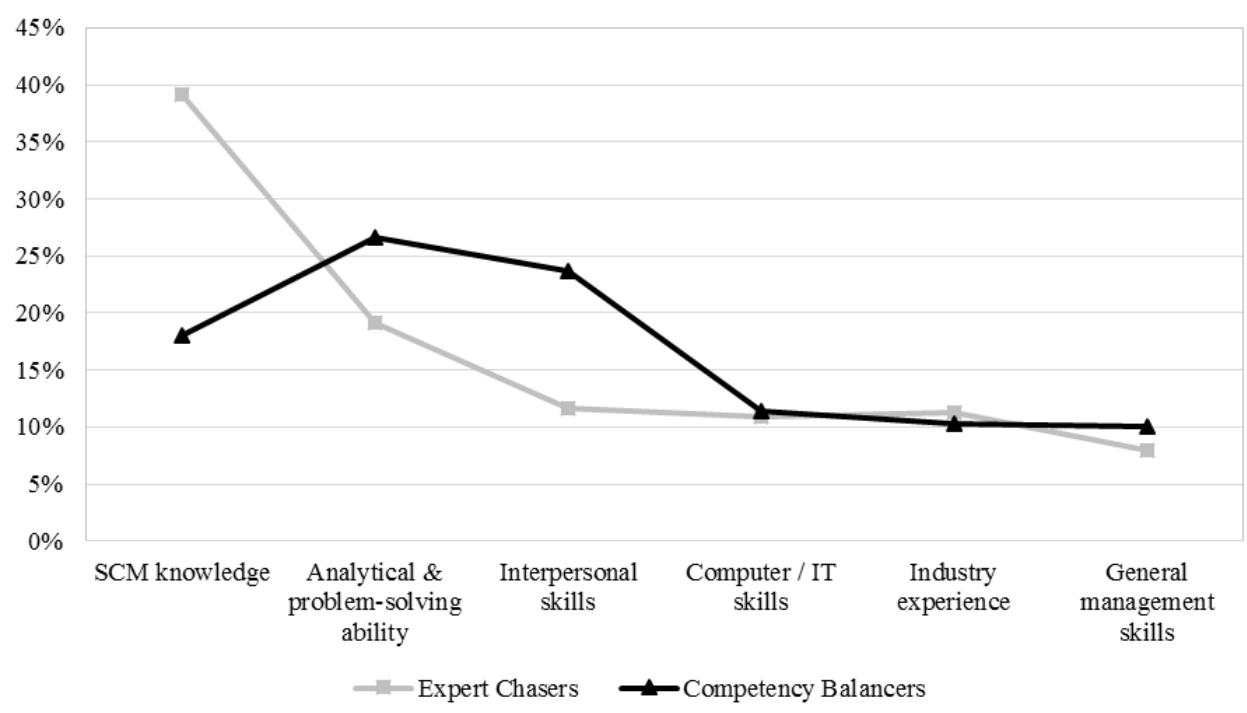

TABLE 1: META-ANALYSIS - TOP 25\% COMPETENCY ITEMS IN THE LITERATURE

\begin{tabular}{cllc}
\hline Rank & Competency & Category $)^{1)}$ & $\begin{array}{c}\text { Aggregated mean } \\
\text { (scale: 1-5) }\end{array}$ \\
\hline $\mathbf{1}$ & Personal integrity & Interpersonal skills & 4.767 \\
$\mathbf{2}$ & Motivating others & Interpersonal skills & 4.747 \\
$\mathbf{3}$ & Organization and planning & General management skills & 4.653 \\
$\mathbf{4}$ & Self-motivation & Analytical \& problem-solving ability & 4.597 \\
$\mathbf{5}$ & Managerial control & General management skills & 4.563 \\
$\mathbf{6}$ & Persuasion & Interpersonal skills & 4.553 \\
$\mathbf{7}$ & Change management & General management skills & 4.543 \\
$\mathbf{8}$ & Delegate responsibility & Interpersonal skills & 4.537 \\
$\mathbf{9}$ & Problem-solving ability & Analytical \& problem-solving ability & 4.531 \\
$\mathbf{1 0}$ & Customer service & General management skills & 4.530 \\
$\mathbf{1 1}$ & Supervision & Interpersonal skills & 4.523 \\
$\mathbf{1 2}$ & Negotiation & General management skills & 4.510 \\
$\mathbf{1 3}$ & Expertise in interpersonal relations & Interpersonal skills & 4.510 \\
$\mathbf{1 3}$ & Transportation \& logistics & Functional expertise & 4.498 \\
$\mathbf{1 5}$ & Self-confidence & Analytical \& problem-solving ability & 4.493 \\
$\mathbf{1 6}$ & Strategic thinking & General management skills & 4.470 \\
$\mathbf{1 7}$ & Viewing a firm as a system & Analytical \& problem-solving ability & 4.467 \\
$\mathbf{1 8}$ & Effective communication & Interpersonal skills & 4.443 \\
$\mathbf{1 9}$ & Conflict resolution & Analytical \& problem-solving ability & 4.440 \\
$\mathbf{2 0}$ & Listening & Interpersonal skills & 4.387 \\
$\mathbf{2 1}$ & Decision-making & Analytical \& problem-solving ability & 4.354 \\
$\mathbf{2 2}$ & Enthusiasm & Analytical \& problem-solving ability & 4.343 \\
$\mathbf{2 3}$ & Analytical & Analytical \& problem-solving ability & 4.330 \\
\hline
\end{tabular}

Note: Scale: $1=$ not important at all, $5=$ very important

1) According to the Mangan \& Christopher's (2005) framework 
TABLE 2: SIX COMPETENCY ATTRIBUTES WITH LEVELS AS SHOWN TO THE PARTICIPANTS

\begin{tabular}{|c|c|c|}
\hline Attributes & Levels & Examples \\
\hline $\begin{array}{l}\text { Analytical and problem- } \\
\text { solving abilities }\end{array}$ & Very good & $\begin{array}{l}\text { Very good in the respective category, e.g., } \\
\text { - Interpersonal skills: very good listener, very strong team player and communicator }\end{array}$ \\
\hline Computer / IT skills & Good & $\begin{array}{l}\text { - Computer / IT skills: outstanding skills in company- and job-relevant software packages } \\
\text { - ... } \\
\text { Good in the respective category, e.g., } \\
\text { - General management skills: good project manager, good sense of financial metrics } \\
\text { - Analytical and problem-solving ability: quick analyzer of large amount of data }\end{array}$ \\
\hline General management skills & & $\cdot \cdots$ \\
\hline Interpersonal skills & Basic & $\begin{array}{l}\text { Basic in the respective category, e.g., } \\
\text { - General management skills: able to manage multiple tasks at the same time } \\
\text { - Computer / IT skills: has worked with relevant software packages before } \\
\text { - ... }\end{array}$ \\
\hline \multirow[t]{2}{*}{ Industry experience } & Extensive & $\begin{array}{l}\text { Extensive knowledge/experience, e.g., } \\
\text { - Industry experience: several years of working experience in the same industry } \\
\text { - ... }\end{array}$ \\
\hline & Some & $\begin{array}{l}\text { Some knowledge/experience, e.g., } \\
\text { - SCM knowledge: previous intersections with SCM, or SCM lectures in college } \\
\text { - } \ldots\end{array}$ \\
\hline SCM knowledge & None & $\begin{array}{l}\text { None }- \text { no knowledge/experience, e.g., } \\
\text { - Industry experience: No prior work in the same or a related industry } \\
\text { - ... }\end{array}$ \\
\hline
\end{tabular}

\section{TABLE 3: DESCRIPTIVE SAMPLE STATISTICS}

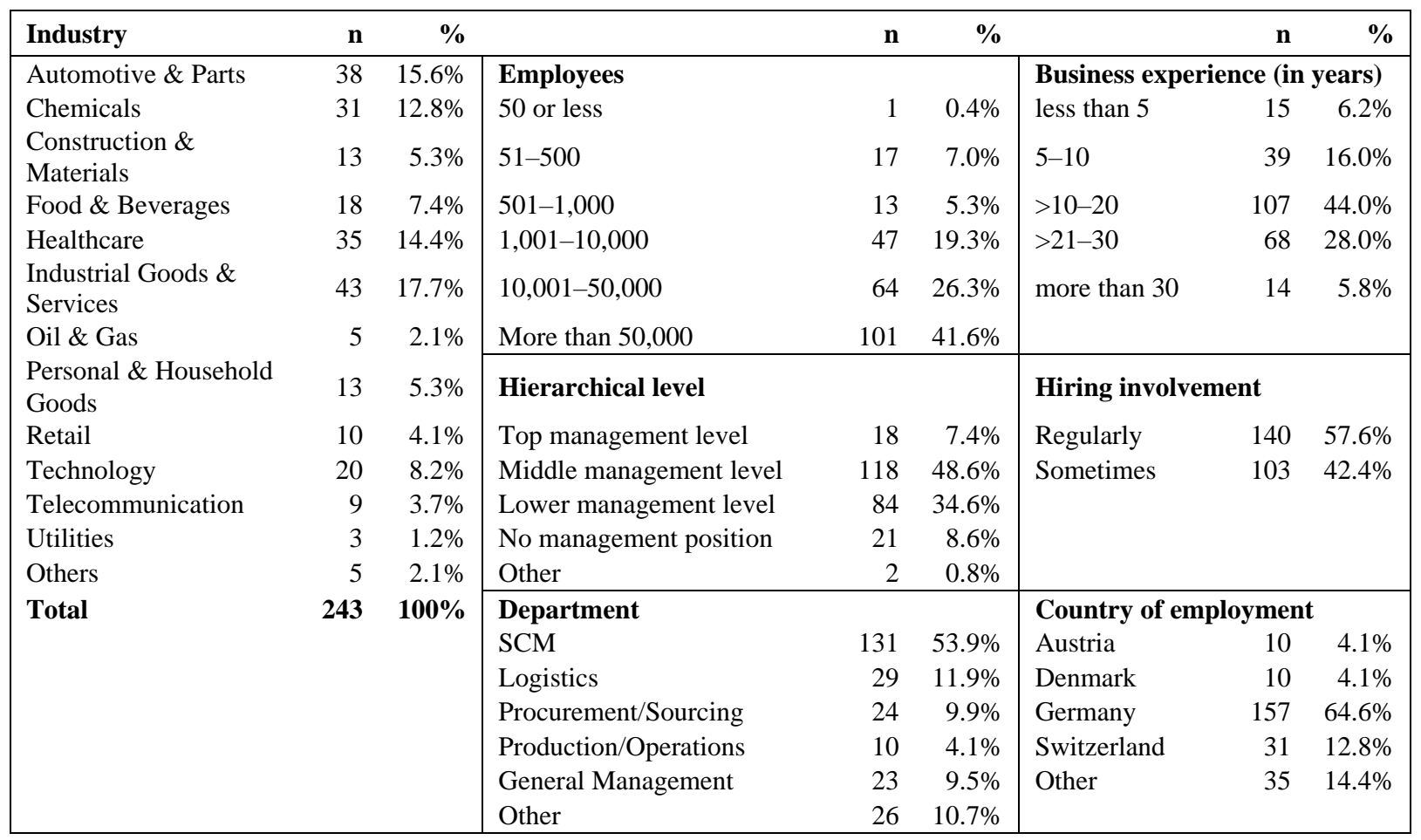


TABLE 4: AVERAGE UTILITIES AND RELATIVE ATTRIBUTE IMPORTANCE

\begin{tabular}{lrrrrr}
\hline Attributes \& Levels & $\begin{array}{r}\text { Average } \\
\text { Utilities }\end{array}$ & $\begin{array}{r}\text { Standard } \\
\text { Deviation }\end{array}$ & $\begin{array}{r}\text { Lower } \\
\mathbf{9 5 \%} \text { CI }\end{array}$ & $\begin{array}{r}\text { Upper } \\
\mathbf{9 5 \%} \text { CI }\end{array}$ & $\begin{array}{r}\text { Relative } \\
\text { importance }\end{array}$ \\
\hline SCM knowledge & & & & & $\mathbf{2 6 . 0 \%}$ \\
$\quad$ Extensive & 72.3 & 36.4 & 67.8 & 76.9 & \\
$\quad$ Some & 9.7 & 20.4 & 7.2 & 12.3 & \\
$\quad$ None & -82.1 & 44.6 & -87.7 & -76.5 & \\
$\quad$ Analytical \& problem-solving ability & & & & & $\mathbf{2 3 . 8 \%}$ \\
$\quad$ Very good & 62.8 & 22.2 & 60.0 & 65.6 & \\
$\quad$ Good & 16.4 & 17.3 & 14.3 & 18.6 & \\
$\quad$ Basic & -79.2 & 34.8 & -83.6 & -74.8 & \\
Interpersonal skills & & & & & $\mathbf{1 9 . 1 \%}$ \\
$\quad$ Very good & 46.5 & 23.6 & 43.5 & 49.4 & \\
$\quad$ Good & 19.4 & 19.9 & 16.9 & 21.9 & \\
$\quad$ Basic & -65.8 & 37.9 & -70.6 & -61.1 & \\
Computer/IT skills & & & & & $\mathbf{1 1 . 2 \%}$ \\
$\quad$ Very good & 28.5 & 17.7 & 26.3 & 30.7 & \\
$\quad$ Good & 7.3 & 10.7 & 5.9 & 8.6 & \\
$\quad$ Basic & -35.8 & 23.7 & -38.7 & -32.8 & \\
Industry experience & & & & & $\mathbf{1 0 . 6 \%}$ \\
$\quad$ Extensive & 31.0 & 19.3 & 28.6 & 33.4 & \\
$\quad$ Some & -0.6 & 11.8 & -2.0 & 0.9 & \\
$\quad$ None & -30.4 & 19.8 & -32.9 & -28.0 & \\
General management skills & & & & & $\mathbf{9 . 3 \%}$ \\
$\quad$ Very good & 24.8 & 17.1 & 22.7 & 27.0 & \\
$\quad$ Good & 1.2 & 11.8 & -0.2 & 2.7 & \\
$\quad$ Basic & -26.0 & 20.3 & -28.6 & -23.5 & \\
\hline Ni Cl cond & & & & & \\
\hline
\end{tabular}


TABLE 5: SEGMENTATION RESULTS

\begin{tabular}{|c|c|c|c|}
\hline $\begin{array}{l}\text { Segments } \\
\text { n } \\
\%\end{array}$ & $\begin{array}{r}\text { Expert Chasers } \\
92 \\
38 \%\end{array}$ & $\begin{array}{r}\text { Competency balancers } \\
151 \\
62 \%\end{array}$ & $\begin{array}{c}\text { Mann-Whitney-U } \\
\text { test }\end{array}$ \\
\hline SCM knowledge & $39.1 \%$ & $18.0 \%$ & $* * *$ \\
\hline Extensive & 107.7 & 50.8 & $* * *$ \\
\hline Some & 17.9 & 4.7 & $* * *$ \\
\hline None & -125.7 & -55.5 & *** \\
\hline Analytical \& problem-solving ability & $19.1 \%$ & $26.6 \%$ & $* * *$ \\
\hline Very good & 51.9 & 69.4 & $* * *$ \\
\hline Good & 10.2 & 20.2 & $* * *$ \\
\hline Basic & -62.1 & -89.7 & *** \\
\hline Interpersonal skills & $11.6 \%$ & $23.7 \%$ & $* * *$ \\
\hline Very good & 30.7 & 56.0 & $* * *$ \\
\hline Good & 4.4 & 28.5 & $* * *$ \\
\hline Basic & -35.2 & -84.5 & $* * *$ \\
\hline Computer/IT skills & $10.9 \%$ & $11.4 \%$ & \\
\hline Very good & 27.4 & 29.2 & \\
\hline Good & 7.4 & 7.2 & \\
\hline Basic & -34.8 & -36.4 & \\
\hline Industry experience & $11.2 \%$ & $10.3 \%$ & \\
\hline Extensive & 32.0 & 30.3 & \\
\hline Some & -0.4 & -0.7 & \\
\hline None & -31.7 & -29.7 & \\
\hline General management skills & $8.0 \%$ & $10.1 \%$ & $* * *$ \\
\hline Very good & 21.1 & 27.1 & $* * *$ \\
\hline Good & 1.4 & 1.1 & \\
\hline Basic & -22.5 & -28.2 & ** \\
\hline \multicolumn{4}{|l|}{ Covariates $^{1)}$} \\
\hline Possible over-qualification of candidate & & & $*$ \\
\hline Functional background of respondent & & & * \\
\hline Social commitment of candidate & & & * \\
\hline Nagelkerke's R ${ }^{2}$ & & & 0.112 \\
\hline
\end{tabular}

Note: $* * * \mathrm{p}<0.01, * * \mathrm{p}<0.05, * \mathrm{p}<0.1$

Relative importance $(\%)$ of attributes in bold

1) Predictors of group affiliation tested with binomial logistic regression: model chi $^{2}=20.87, p=0.076^{*}$

The following covariates were also included in the demographic section as control variables, but none of them differed significantly statistically across segments: SCM strategy (efficient vs responsive), business, industry, and company experience of respondents (years), reputation of the SCM planning function in the firm, extent of HRM-SCM collaboration, industry, country, and firm size (employees). 